\title{
Basketball game-related statistics that discriminate between teams' season-long success
}

\author{
SERGIO J. IBÁÑEZ , JAIME SAMPAIO , SEBASTIAN FEU , ALBERTO LORENZO , \\ MIGUEL A. GÓMEZ , \& ENRIQUE ORTEGA
}

Faculty of Sport Sciences, University of Extremadura, Sport Sciences Department, University of Trás-os-Montes e Alto Douro, Faculty of Physical Activity and Sport Sciences, Polytechnic University of Madrid, and Faculty of Health, Physical Activity, and Sport Sciences, Catholic University Saint Anthony of Murcia, Spain

\begin{abstract}
The aim of the present study was to identify the game-related statistics that discriminate between season-long successful and unsuccessful basketball teams participating in the Spanish Basketball League (LEB1). The sample included all 145 average records per season from the 870 games played between the 2000-2001 and the 2005-2006 regular seasons. The following game-related statistics were gathered from the official box scores of the Spanish Basketball Federation: 2- and 3-point fieldgoal attempts (both successful and unsuccessful), free-throws (both successful and unsuccessful), defensive and offensive rebounds, assists, steals, turnovers, blocks (both made and received), and fouls (both committed and received). To control for season variability, all results were normalized to minutes played each season and then converted to $z$-scores. The results allowed discrimination between best and worst teams' performances through the following game-related statistics: assists $(\mathrm{SC}=0.47)$, steals $(\mathrm{SC}=0.34$ ), and blocks ( $\mathrm{SC}=0.30$ ). The function obtained correctly classified $82.4 \%$ of the cases. In conclusion, season-long performance may be supported by players' and teams' passing skills and defensive preparation.
\end{abstract}

Keywords: Basketball, discriminant analysis, professional league, game-related statistics

\section{Introduction}

The study of basketball game-related statistics in competition has been used to identify variables that can distinguish between successful teams and players, which can lead to better sport results. Indeed, this field of research has recently become a subject of practical and scientific interest to coaches and sport scientists. Globally, available research has shown that basketball winning teams outperform losing teams in shooting field goals and securing defensive rebounds (Akers, Wolff, \& Buttross, 1991; Ibáñez, Sampaio, Sáenz-López, Giménez, \& Janeira, 2003; Ittenbach \& Esters, 1995; Karipidis, Fotinakis, Taxildaris, \& Fatouros, 2001). However, in specific game contexts such as closely contested games, other game-related statistics such as fouls and free-throws exhibit greater importance (Kozar, Vaughn, Whitfield, Lord, \& Dye, 1994). In these studies, other game-related statistics such as offensive rebounds, turnovers, steals, and assists have not been reported as consistently as discriminators between winning and losing teams.

This suggests that winning teams' performances are based on the quality of player decision making and field-goal efficiency and efficacy within a welldefined strategic and tactical team environment (Trninić, Dizdar, \& Lukšić, 2002). Concurrently, the defensive rebounds represent a team's ability to recover the ball after an opponent's missed shots (Trninić et al., 2002). A successful defensive rebounding team has more opportunities to attempt field goals, score points, and win games (Sampaio \& Janeira, 2003). High-level performances in rebounding are associated with players' anthropometric characteristics, muscular fitness, and technical and tactical preparation (Carter, Ackland, Kerr, \& Stappf, 2005). 
These studies contrasted winners and losers of games played during a regular basketball season (Akers et al., 1991; Ittenbach \& Esters, 1995), two regular basketball seasons (Sampaio \& Janeira, 2003), or international championships (Ibáñez et al., 2003; Karipidis et al., 2001). No study has been conducted over several basketball seasons to identify game-related statistics that discriminate season-long success. This information would allow more specific strategic and tactical team preparation, from player recruitment to practice planning, execution, and control. On the other hand, all previous studies have only contrasted winners' and losers' performances. A reasonable question is that game final outcome can be a measure of team success, but only at a given instant, because successful teams can lose some games and unsuccessful teams can win games. Thus, it is possible that a better measure of teams' success would be one that identifies a team's season-long success rather than immediate game performances. Therefore, the aim of the present study was to identify the basketball game-related statistics that discriminate between teams' seasonlong success.

\section{Methods}

\section{Sample and variables}

Data were collected from all 870 games played between the 2000-2001 and 2005-2006 regular seasons (Spanish Basketball League, LEB1). From this sample, 145 average records per season were analysed with all games played over four periods of $10 \mathrm{~min}$, with $24 \mathrm{~s}$ ball possessions. The game-related statistics gathered included: 2- and 3-point field-goal attempts (both successful and unsuccessful), freethrows (both successful and unsuccessful), defensive and offensive rebounds, assists, steals, turnovers, blocks (both made and received), and fouls (both committed and received). To control for game rhythm, all variables were then normalized according to game ball possessions and multiplied by 100 (Kubatko, Oliver, Pelton, \& Rosenbaum, 2007; Oliver, 2004; Sampaio \& Janeira, 2003). Ball possessions (BP) were calculated using the following equation ( $\mathrm{BP}=$ field goals attempts - offensive rebounds + turnovers $-0.4 \times$ attempted free throws) (Kubatko et al., 2007; Oliver, 2004). The offensive efficacy was calculated by dividing team points scored by game ball possessions. All variables were screened for outliers, which were eliminated from the sample. In addition, all variables were normalized according to minutes played in the corresponding season (because the number of competing teams varied across seasons) before being transformed to $z$-scores. This transformation was carried out to provide a normative measure that best compares teams' performances. To measure teams' seasonlong success, all game performances were divided into two categories: best teams (teams that qualified that season for the play-off series, i.e. the first 8 teams) and worst teams (teams that did not qualify that season for the play-off series, i.e. the remaining 8-10 teams).

\section{Statistical analysis}

One-way analysis of variance was carried out to identify differences in game-related statistics between best and worst teams' performances. Then, a discriminant analysis was performed to identify the variables that best discriminate between the groups (Ntoumanis, 2001). Interpretation of the discriminant functions was based on examination of the structure coefficients greater than $|0.30|$ (Tabachnick \& Fidell, 2007). Validation of the discriminant models was conducted using the leave-one-out method of cross-validation (Norušis, 2004). Crossvalidation analysis takes subsets of data for training and testing and is required to understand the usefulness of discriminant functions when classifying new data. This method involves generating the discriminant function on all but one of the participants $(n-1)$ and then testing for group membership of that participant. The process is repeated for each participant ( $n$ times) and the percentage of correct classifications generated through averaging for the $n$ trials. The statistical analyses were performed using SPSS software release 13.0 and statistical significance was set at $P \leq 0.05$.

\section{Results}

Descriptive results from game-related statistics for best and worst teams are presented in Table I, with the best teams exhibiting significantly more successful free-throws, defensive rebounds, assists, steals, blocks, and offensive efficiency, and significantly fewer fouls committed compared with the worst teams (Table I).

The discriminant function obtained was statistically significant $(P<0.01)$ and was able to correctly classify $82.4 \%$ of the cases. The results allowed discrimination between best and worst teams' performances through the following game-related statistics: assists $(\mathrm{SC}=0.47)$, steals $(\mathrm{SC}=0.34)$, and blocks $(\mathrm{SC}=0.30)$. In all cases, the best teams exhibited higher values (Table II).

\section{Discussion}

The aim of the present study was to identify the game-related statistics that discriminate between 
Table I. Game-related results for the sample studied (per 100 ball possessions and per game; mean $\pm \mathrm{s}$ )

\begin{tabular}{lrc}
\hline Game-related statistics & Best teams & Worst teams \\
\hline Successful 2-point field goals & $10.69 \pm 1.61$ & $10.59 \pm 0.96$ \\
Unsuccessful 2-point field goals & $10.07 \pm 1.49$ & $10.02 \pm 0.91$ \\
Successful 3-point field goals & $3.35 \pm 0.42$ & $3.16 \pm 0.54$ \\
Unsuccessful 3-point field goals & $6.10 \pm 0.62$ & $6.15 \pm 0.68$ \\
Successful free-throws & $7.84 \pm 0.81$ & $7.50 \pm 0.71^{\star}$ \\
Unsuccessful free-throws & $3.17 \pm 0.54$ & $3.15 \pm 0.45$ \\
Defensive rebounds & $10.74 \pm 0.67$ & $10.42 \pm 0.64^{\star}$ \\
Offensive rebounds & $4.76 \pm 0.58$ & $4.55 \pm 0.56$ \\
Assists & $5.56 \pm 0.87$ & $4.89 \pm 0.77^{\star}$ \\
Steals & $4.41 \pm 0.73$ & $3.99 \pm 0.57^{\star}$ \\
Turnovers & $7.00 \pm 0.73$ & $7.08 \pm 0.59$ \\
Blocks & $1.44 \pm 0.42$ & $1.15 \pm 0.32^{\star}$ \\
Blocks received & $1.23 \pm 0.20$ & $1.26 \pm 0.24$ \\
Fouls committed & $10.64 \pm 0.79$ & $10.95 \pm 0.83^{\star}$ \\
Fouls received & $10.69 \pm 0.65$ & $10.60 \pm 0.59$ \\
Ball possessions & $56.41 \pm 1.98$ & $56.48 \pm 2.56$ \\
Offensive efficacy & $1.42 \pm 0.07$ & $1.35 \pm 0.07^{\star}$ \\
\hline
\end{tabular}

* Significantly different from best teams $(P \leq 0.05)$.

season-long successful and unsuccessful basketball teams. We reasoned that teams' regular season final classification, instead of game final outcome, would be a more suitable measure of teams' success.

Available research identifies field-goal shooting and defensive rebounds as discriminant statistics between winners and losers of games. However, these game-related statistics are not discriminant, when the criterion is season-long success, as in the present study. In fact, our results suggest that season-long basketball success is discriminated best by performance on assists, steals, and blocks. In essence, this is the profile of a team that exhibits better overall passing skills and better outside and inside defensive pressure.

The assists are an altruistic measure of teamwork and require good decision making in court, coordination, anticipation, timing, and exquisite execution (Gómez, Tsamourtzis, \& Lorenzo, 2006; Melnick, 2001). Other researchers have reported that assists were a discriminating game-related statistic between senior and junior basketball players' performances, suggesting that this is also a measure of player and team experience and maturity (Sampaio, Ibáñez, \& Feu 2004). These actions are mostly performed by guards (Sampaio, Janeira, Ibáñez, \& Lorenzo, 2006; Taxildaris et al., 2001). Therefore, it is suggested that the best teams have players in this specific position better prepared to execute these tasks, building in practices and promoting in competition a stronger within-team offensive communication (Heuzé, Rainbault, \& Fontayne, 2006).

The steals and blocks are a measure of better outside and inside defensive pressure, respectively. In fact, ball steals occur mostly outside the court restrictive area and are usually performed by guards and forwards (Miller \& Bartlett, 1996; Sampaio
Table II. Discriminant function structure coefficients (SC) and tests of statistical significance.

\begin{tabular}{lc}
\hline Game-related statistics & $\mathrm{SC}$ \\
\hline Assists & $0.47^{\star}$ \\
Steals & $0.34^{\star}$ \\
Blocks & $0.30^{\star}$ \\
Fouls committed & -0.24 \\
Successful free-throws & 0.22 \\
Defensive rebounds & 0.20 \\
Successful 3-point field goals & 0.16 \\
Offensive rebounds & 0.16 \\
Successful 2-point field goals & 0.08 \\
Unsuccessful 2-point field goals & -0.08 \\
Fouls received & 0.07 \\
Blocks received & -0.06 \\
Turnovers & -0.05 \\
Unsuccessful 3-point field goals & -0.04 \\
Unsuccessful free-throws & 0.02 \\
Eigenvalue & 1.17 \\
Wilks' lambda & 0.46 \\
Canonical correlation & 0.73 \\
Chi-squared & 71.19 \\
Significance & 0.00 \\
Reclassification & $82.4 \%$ \\
\hline
\end{tabular}

${ }^{\star} \mathrm{SC}$ discriminant value $\geq|0.30|$.

et al., 2006). Players' assertiveness and fitness have a strong influence in these tasks (Dežman, Trninić, \& Dizdar, 2001; Trninić, Dizdar, \& Dežman, 2000). In addition, effective team defensive communication can lead to increased defensive pressure in all passing spots, and ultimately to passes that are easier to steal (Otto, 1998). Also, it has been suggested that less effective teams use ball dribbling more frequently (Gómez et al., 2006), which can increase the probability of a steal. On the other hand, blocks occur mostly inside the court restrictive area and are usually performed by centres (Sampaio et al., 2006; Sporiš, Šango, Vučetić, \& Mašina, 2006). Centres' anthropometric and technical characteristics appear to have an important influence in these defensive tasks. Also, because they are the tallest and strongest defenders and the nearest to the basket, they also play a role in intimidating opponents' field-goal attempts (Trninić et al., 2000). In fact, the execution of blocks depends mostly upon player height, jumping ability, and coordination, as well as on adequate technique (Papadimitrou, Taxildaris, Derri, \& Mantis, 1999). Again, an effective team defensive communication can leave the opposing centres with no option but to attempt a field goal with a greater chance of it being blocked. Therefore, the current results seem to suggest that the best teams have players who are better prepared to execute these game defensive tasks, outside and inside the court restrictive area.

There were no statistically significant differences between best and worst teams' game ball possessions, which are a reflection of game rhythm (Oliver, 
2004). Our results suggest that in basketball, overall team success is not associated with higher or lower game rhythms. On the other hand, the best teams did exhibit higher offensive efficacies than the worst teams $(1.42 \pm 0.07$ vs. $1.35 \pm 0.07, P \leq 0.05)$. These results suggest that success depends upon how basketball teams manage their opportunities to score points. Thus, it appears that high-level basketball team success is not dependent on how many opportunities the team has to score but on how to profit from current opportunities. From a practical viewpoint, coaches can use these ratings to help establish more objective goals in game practices. For example, in each of five ball possessions the best teams were able to score more than 7 points $(1.42$ rating $\times 5$ ball possessions).

\section{Conclusions}

Our results suggest a number of differences between best and worst teams' game-related statistics, but globally the offensive (assists) and defensive (steals and blocks) actions were the most powerful factors in discriminating between groups. Therefore, game winners and losers are discriminated by defensive rebounding and field-goal shooting, whereas season-long performance is discriminated by players' and teams' passing skills and defensive preparation. Players should be better informed about these results and it is suggested that coaches pay attention to guards' passing skills, to forwards' stealing skills, and to centres' blocking skills to build and prepare offensive communication and overall defensive pressure.

\section{References}

Akers, M. D., Wolff, S., \& Buttross, T. (1991). An empirical examination of the factors affecting the success of NCAA Division I College Basketball teams. Fournal of Business and Economic Studies, 1, 57-71.

Carter, J. E. L., Ackland, T. R., Kerr, D. A., \& Stappf, A. B. (2005). Somatotype and size of elite female basketball player. fournal of Sports Sciences, 23, 1057-1063.

Dežman, B., Trninić, S., \& Dizdar, D. (2001). Expert model of decision-making system for efficient orientation of basketball players to positions and roles in the game-empirical verification. Collegium Antropologicum, 25, 141-152.

Gómez, M. A., Tsamourtzis, E., \& Lorenzo, A. (2006). Defensive systems in basketball ball possessions. International fournal of Performance Analysis in Sport, 6, 98-107.

Heuzé, J. P., Rainbault, N., \& Fontayne, P. (2006). Relationships between cohesion, collective efficacy and performance in professional basketball teams: An examination of mediating effects. Fournal of Sports Sciences, 24, 59-68.
Ibáñez, S. J., Sampaio, J., Sáenz-López, P., Giménez, J., \& Janeira, M. A. (2003). Game statistics discriminating the final outcome of Junior World Basketball Championship matches (Portugal 1999). Fournal of Human Movement Studies, 45, 1-19.

Ittenbach, R. F., \& Esters, I. G. (1995). Utility of team indices for predicting end of season ranking in two national polls. Fournal of Sport Behavior, 18, 216-225.

Karipidis, A., Fotinakis, P., Taxildaris, K., \& Fatouros, J. (2001). Factors characterising a successful performance in basketball. Fournal of Human Movement Studies, 41, 385-397.

Kozar, B., Vaughn, R. E., Whitfield, K. E., Lord, R. H., \& Dye, B. (1994). Importance of free-throws at various stages of basketball games. Perceptual and Motor Skills, 78, 243-248.

Kubatko, J., Oliver, D., Pelton, K., \& Rosenbaum, D. (2007). A starting point for analyzing basketball statistics. fournal of Quantitative Analysis in Sports, 3, 1-22.

Melnick, M. J. (2001). Relationship between team assists and win-loss record in the National Basketball Association. Perceptual and Motor Skills, 92, 595-602.

Miller, S., \& Bartlett, R. (1996). The relationship between basketball shooting kinematics, distance and playing position. Fournal of Sports Sciences, 14, 243-253.

Norušis, M. J. (2004). SPSS 13.00 Advanced statistical procedures companion. Englewood-Cliffs, NJ: Prentice-Hall.

Ntoumanis, N. (2001). A step-by-step guide to SPSS for sport and exercise studies. London: Routledge.

Oliver, D. (2004). Basketball on paper: Rules and tools for performance analysis. Washington, DC: Brassey's, Inc.

Otto, K. (1998). Defense wins! Scholastic Coach and Athletic Director, 67, 24-25.

Papadimitrou, K., Taxildaris, K., Derri, V., \& Mantis, K. (1999). Profile of different level basketball centers. Fournal of Human Movement Studies, 37, 87-105.

Sampaio, J., Ibáñez, S. J., \& Feu, S. (2004). Discriminative power of basketball game-related statistics by level of competition and sex. Perceptual and Motor Skills, 99, 1231-1238.

Sampaio, J., \& Janeira, M. (2003). Statistical analyses of basketball team performance: Understanding teams' wins and losses according to a different index of ball possessions. International Fournal of Performance Analysis in Sport, 3, 40-49.

Sampaio, J., Janeira, M., Ibáñez, S., \& Lorenzo, A. (2006). Discriminant analysis of game-related statistics between basketball guards, forwards and centres in three professional leagues. European fournal of Sport Science, 6, 173-178.

Sporiš, G., Šango, J., Vučetić, V., \& Mašina, T. (2006). The latent structure of standard game efficiency indicators in basketball. International Fournal of Performance Analysis in Sport, 6, 120129.

Tabachnick, B., \& Fidell, L. (2007). Using multivariate statistics (5th edn). New York: Allyn \& Bacon.

Taxildaris, K., Papadimitriou, K., Alexopoulos, P., Fatouros, I. G., Kambas, A., Karipidis, A., et al. (2001). Factors characterizing the offensive game of the playmaker position in basketball. fournal of Human Movement Studies, 40, 405-421.

Trninić, S., Dizdar, D., \& Dezman, B. (2000). Empirical verification of the weighted system of criteria for the elite basketball players quality evaluation. Collegium Antropologicum, 24, 443-465.

Trninić, S., Dizdar, D., \& Lukšić, E. (2002). Differences between winning and defeated top quality basketball teams in final tournaments of European club championship. Collegium Antropologicum, 26, 521-531. 